\title{
Siirt Arapçasının Korunmasında Sözlü Kültürün Rolü
}

\begin{abstract}
iD Emin Cengiz*
Atıf/@: Cengiz, Emin, Siirt Arapçasının Korunmasında Sözlü Kültürün Rolü, Artuklu Akademi 2019/6 (1), 67-88.

Öz: Arapça, günümüzde çok geniş bir coğrafyada konuşulan dünyanın en köklü dillerinden birisidir. Türkiye'nin Güney ve Güneydoğu illerinde de Arapçaya ait lehçeleri konuşan insanlar bulunmaktadır. Bu bölgelerden birisi de Siirt ilidir. Bu yörede yaşayan Araplar kendi dillerini yazılı kültürden yoksun bir şekilde tamamen sözlü geleneğe dayanarak asırlar boyunca muhafaza etmeyi başarabilmişlerdir. Tarihi süreç içerisinde doğal olarak oluşan sözlü kültür, yöre halkının kimliğini oluşturan bütün kodları içinde barındıran bir kara kutu mahiyetindedir. Bunun yanı sıra Siirt Arapça diyalektinde kullanılan sözlü edebiyat ürünleri, söz konusu lehçenin muhafazası ve gelecek kuşaklara aktarılması noktasında önemli bir rol üstlenmiştir. Bu çalışmada Siirt Arapça diyalektinin sözlü edebiyat ürünleri ve bu ürünlerin söz konusu lehçenin korunmasındaki rolü ele alınacaktır.
\end{abstract}

Anahtar Kelimeler: Siirt Arapçası, Diyalekt, Dilbilim, Sözlü Edebiyat, Sözlü Kültür.

\section{The Role of the Oral Culture in the Protection of Siirt Arabic Dialects}

Citation/@: Cengiz, Emin, The Role of the Oral Culture in the Protection of Siirt Arabic Dialects, Artuklu Akademi 2019/6 (1), 67-88.

Abstract: Arabic is one of the ancient and most widely spoken languages in the world today. In the regions that extend to the south and southeast of Turkey, there are people who speak dialects of Arabic. One of these regions is Siirt province. Arabs living in this region have managed to preserve their native languages for centuries, without any written culture, on the basis of a completely oral tradition. Oral culture, which is formed naturally in the historical process, is the black box that contains all the codes that constitute the identity of the people of the region. In addition, the oral literature products used in Siirt Arabic dialect have played an important role in preserving the dialect and transferring it to future generations. In this study, the oral literature products of Siirt Arabic dialect and the importance of these products in the protection of dialect will be discussed.

Keywords: Siirt Arabic, Dialect, Linguistics, Oral Literature, Oral Culture [The Extended Abstract is at the end of the article.]

Dr. Öğr. Üyesi, Şırnak Üniversitesi İlahiyat Fakültesi Arap Dili ve Belagatı Anabilim Dalı, fatihemin@hotmail.com. 


\section{Giriş}

Canlılar arasında birçok iletişim şekli vardır. İnsanlar da el-kol hareketlerini ve mimiklerini kullanarak iletişim kurabilmektedir. Ancak insanoğlunu diğer canlılardan ayıran en önemli özelliği konuşabiliyor olmasıdır. İletişimin esası ve en gelişmiş hali, dil ve dili yansıtan seslerdir. Esasında yazı da bu sesleri yansıtmaya yarayan sembollerden başka bir şey değildir. Dolayısıyla bir ses ürünü olan dilin temelde sözlü bir iletişim aracı olduğunu söylemek yanlış olmasa gerektir. İnsanlık tarihi boyunca konuşulan binlerce dilden çok azı bir edebiyat oluşturabilmişken, bugün bile konuşulmakta olan yüzlerce dilin bir yazılı sistemi bulunmamaktadır. ${ }^{1}$

Türkiye'nin Güney ve Güneydoğu hattında uzanan bölgelerde Arapçaya ait lehçeleri konuşan halklar bulunmaktadır. En son 2007 yılında yapılan anadil araştırmalarına göre Türkiye'de bir milyonu aşkın kişinin Arapçayı anadil olarak belirttiği tespit edilmiştir. Bu dili konuşanlar daha çok Mersin, Adana, Hatay, Gaziantep, Kilis, Şanlıurfa, Mardin, Diyarbakır, Batman, Siirt, Muş ve Bitlis gibi illerde yoğunlaşmaktadır.² Ayrıca bu illerden göç eden ve özellikle Batıdaki büyük kentlere yerleşen Arap asıllı vatandaşların sayılarının az olmadığı bilinmektedir. ${ }^{3}$ Türkiye'deki Araplar, kendi dillerini yazılı kültürden yoksun bir şekilde tamamen sözlü geleneğe dayanarak asırlar boyunca muhafaza etmeyi başarabilmişlerdir. Arapların yoğun olarak yaşadığı bölgelerden birisi de Siirt ilidir. Bu yörede Arapların yanı sira Kürtler, Türkler, Ermenîler, Süryânîler ve Keldânîler uzun yıllar boyunca iç içe yaşamışlardır. ${ }^{4}$

Bu çalışmada Siirt il merkezi ve Rıstâk bölgesinde ${ }^{5}$ konuşulan ve Arap diline ait bir lehçe olarak kabul edilen Siirt Arapçasının sözlü kültür unsurlarının bu dilin korunmasındaki rolü incelenecektir. Bu anlamda sözlü kültür ürünlerinden olan hikâye, masal, bilmece, tekerleme, atasözü ve deyimlerden birtakım örnekler sunulacak ve bu ürünlerin lehçenin ayakta kalma-

1 Walter J. Ong, Sözlü ve Yazılı Kültür Sözün Teknolojileşmesi, 6. bs., çev. Sema Postacıoğlu Banon. (İstanbul: Metis Yayınları, 2018), 19.

2 İnan Keser, Sadullah Seyidoğlu, Türkiye'nin Doğusunda Araplar, 1. bs., (Ankara: Karahan Kitabevi, 2018$), 4$.

3 Bk. Ferman Salmış, Türkiyénin Dil Hafizası, 1. bs., ed. Suat Hayri Küçük, (İstanbul: Librum Kitap, 2015),107.

4 Necim Gül, Siirt Arapçasını Kurtarmak, (ys: Sage Matbaacılık, 2013),10-15; Gabriel Bituna, Morfo-Sintaxa Dıalectului Arab Nord-Mesopotamian Din Siirt, Turcia, (Bükreş: Bükreş Üniversitesi Yayınevi, 2016), 19.

5 Rıstâk bölgesi; Siirt'in Tillo ilçesi, Sínép (Çatılı köyü), Fírsef (Dereyamaç köyü), Halenzé (Siirt'e bağlı Bağtepe mahallesi), Tôm (İkizbağlar köyü) 'Elenzok (Akyamaç köyü) ve Fískén Doluharman köyü)'den oluşan bölgedir. Bu yörenin insanları eskiden tamamen Arapça konuşurken günümüzde ise Tillo ve 'Elenzôk gibi bu bölgenin bazı yerlerinde Kürtçe konuşan halklar da yerleşmiş bulunmaktadır. Bkz. Emin Cengiz, "Siirt Arapçasını Yaşatmak", Türkiye'de Konuşulan Arap Diyalektleri, ed. Yaşar Acat, 1. bs., (İstanbul: Akdem Yayınları, 2018), 224. 
sında üstlendikleri role vurgu yapılacaktır. Hiç şüphesiz bir yazılı dili olmayan Siirt Arapçasının en önemli dayanakları, şifahi kültürün bu dinamikleridir. Dolayısıyla toplumun ortak hafızası ve birikimiyle oluşmuş ve asırlardır sözlü olarak aktarılmak suretiyle yaşatılmış bu ürünlerin kayıt altına alınarak korunması büyük önem arz etmektedir.

Siirt Arapçası uzun yıllar boyunca varlığını sürdürmeyi başarmış olsa da bu süreçte hem ses hem yapı anlamında özünden çok şey kaybetmiştir. Nitekim kökü Arapça olmakla birlikte bu diyalekt, bölgede konuşulan Kürtçe ve Türkçe gibi dillerden etkilenmiş, bu dillerden birtakım ödünç kelime ve yapılar almışır. ${ }^{6}$ Örneğin fasih Arapçada bulunan peltek harfler bu lehçede tamamen kullanımdan kalkarken, iletişime geçilen diğer dillerden de yeni sesler ödünç alınmıştır. Bunun yanı sıra telaffuzda kolaylık maksadıyla bazı peltek harfler, mahreçleri yakın olan başka seslere dönüştürülmüştür. Örneğin " harfinin "f" sesiyle, "ط" ve "ض" harflerinin "w" harfiyle seslendirilmesi gibi bu lehçenin kendine özgü birtakım fonetik özellikleri vardır. Dolasıyla Siirt Arapça diyalektinin ele alındığı bu çalışmada Arap alfabesinin yanında bu lehçeyi en doğru ve en işlevsel şekilde yansıtabilmek adına Latin harfleri de kullanılmıştır. Bunun yanında Arapçayı latinize ederken Latin alfabesine birtakım transkripsiyon işaretleri eklenmiştir. Söz konusu lehçenin kendine has bir ses yapısı olduğu için standart transkripsiyon sistemlerinin dışına çıkılmış, lehçeye özel bir sistem geliştirilmiştir. ${ }^{7}$ Aşağıdaki tabloda Siirt Arapçası için kullanılan alfabe ve transkripsiyon sisteminin ayrıntıları verilmiştir.

\section{Sesli harfler}

\begin{tabular}{|c|c|c|}
\hline$\xi_{\xi} \tilde{\tau} T: \hat{A} \hat{a} / \hat{E} \hat{e}$ & - : $\hat{I} \hat{1}$ & $\hat{g}: \hat{U} \hat{u}$ \\
\hline$\therefore: \mathrm{A} \mathrm{a}, \mathrm{E} \mathrm{e}$ & $-: \dot{I} \mathrm{i}$ & $\therefore: U u$ \\
\hline
\end{tabular}

\section{Sessiz harfler}

\begin{tabular}{|c|c|c|c|c|c|c|}
\hline$\tau: H \mathrm{~h}$ & $\tau: H h$ & ج:C C & $ث: \mathrm{Ff}$ & ت:T t & : B b & s:' \\
\hline ص:S S & ش:Ş Ş & س:S s & $j: Z z$ & $ر: \mathrm{R} \mathrm{r}$ & $\therefore: W w$ & $2: \mathrm{D} \mathrm{d}$ \\
\hline
\end{tabular}

\footnotetext{
Bituna, Morfo-Sintaxa Dialectului Arab, 11-12.

7 Siirt Arapçasının fonetik yapısı ve değişime uğrayan seslerine dair ayrıntılı bilgi için bk. Cengiz, "Siirt Arapçasını Yaşatmak", 229-241.
} 


\begin{tabular}{|c|c|c|c|c|c|c|}
\hline ق : K k & ف:Ff & $\dot{\varepsilon}: \breve{G} \breve{g}$ & $\varepsilon:{ }^{\prime}$ & b:Ww & $b: T t$ & ض:Ww \\
\hline ي:Yy & $9: \mathrm{Vv}$ & $ه: H h$ & $ن: N n$ & :Mm & $J: L 1$ & s : K k \\
\hline
\end{tabular}

\section{İlave Edilen Harfler}

\begin{tabular}{|l|l|l|l|l|}
\hline 巨: Çç & $\xi: \mathrm{Gg}$ & $و: \mathrm{Oo}$ & $\longleftarrow: \mathrm{Pp}$ & $j: \mathrm{Jj}$ \\
\hline
\end{tabular}

Bu yazım sisteminin yanı sıra Siirt Arapçasının ses yapısında, Latin alfabesinde de bulunmayan é ve í gibi sesler de bulunmaktadir. Resmi Arapçada imâle diye tabir edilen é (L) harfi, e ile i arasında bir sesi ifade eder. Örneğin sené (y1l) ve qasabé (ciğer) gibi kelimelerin telaffuzunda görüldüğü gibi genellikle dişillik/müenneslik te'sinin (ö) karşılığı olarak kullanılır. Siirt Arapçasına has bir ses olan í harfi ise e, i ve u seslerinin karışımından çıkan bir ses olup genellikle fasih Arapçadaki i (kesra) sesinin değişime uğramasıyla oluşmuştur. Örneğin sítté (altı) ve míncél (keser) gibi kelimelerde bu sesin kullanıldığı görülmektedir. ${ }^{8}$

\section{Siirt Arapçasında Sözlü Kültür}

Temelde sese dayalı olan dilin en önemli dayanaklarından birisi de yazıdır. Bir yazılı kültürü olmayan dillerin zamanla aşınması, değişmesi ve en vahimi de ölüp yok olması daha kolaydır. Yazı, bir yandan dili dış etkenlerden koruyan bir kale vazifesi görürken, diğer yandan dilin kelime dağarcı̆̆ının zayıflamasını önler ve kelimelerin geçmişleriyle bağlarının kopmasını engeller. ${ }^{9} \mathrm{Bu}$ anlamda Kur'ân-1 Kerîm hem Arap dilinin en fasih dil malzemesini bir araya getirerek bu dilin tüm lehçelerini kucaklamış hem de standart ve fasih Arapçayı tesis ederek Arapçayı muhafaza altına almıştır. ${ }^{10}$

Çok kültürlü ve çok dilli bir coğrafya olan Siirt ilinin kendine has bir Arapçası vardır. Tamamen sözlü geleneğe dayanan bu dilin hem ses hem de kelime ve yapı çeşitliliği bakımından oldukça zengin olduğu söylenebilir. Sanki her sözcüğün yan yana geldiği diğer kelimelere göre özel bir seslendirilişi vardır.

8 Emin Cengiz, "Türkçenin Siirt Arapçasına Etkisi”, Dil Bilimleri Klasik Sorunlar-Güncel Tartışmalar, ed. M. Nesim Doru, Ömer Bozkurt, (Ankara: Mardin Artuklu Üniversitesi Yayınları, Mardin Sesi Gazetecilik Matbaacılık Yayıncılık, 2018), 713.

9 Ong, Sözlü ve Yazılı Kültür, 20.

10 Ahmet Gül, "Sahâbe Tefsirinde Dil Olgusu”, XII. Tefsir Akademisyenleri Koordinasyon Toplantısi: Kur'an ve Sahâbe Sempozyumu (22-23 Mayıs 2015/Sivas), ed. Hasan Keskin, Abdullah Demir, (Sivas 2016), 202. 
Bu dilin ayakta kalmasını sağlayan en önemli faktörlerden birisi, sahip olduğu zengin sözlü kültürüdür. Siirtli Arapların gelenek ve göreneklerini, örf ve adetlerini, yaşam tarzlarını, inançlarını ve dünya görüşlerini çok net bir şekilde yansıtan sözlü kültür unsurları, lehçenin ayakta kalmasında da önemli bir rol üstlenmiştir. Günlük hayatta kullanılmayan veya çok fazla deforme olan bazı orijinal Arapça kelimelerin sözlü edebiyat ürünlerinde yaşamaya ve korunmaya devam ettiği görülmüştür. Şayet bu dinamikler olmasaydı, söz konusu dil malzemesinin çoktan unutulup yok olacağı değerlendirilmektedir.

Dünyanın en gelişmiş diline sahip bir insan, tek başına bir adaya bırakılırsa, onun zamanla kullanılmayan ve aktarılmayan bu becerisinin köreleceği muhakkaktır. Dolayısıyla dillerin yaşayabilmesi için aktif olarak kullanılması ve başkalarına aktarılması gerekir. Bu aktarım temelde söz ile yapılmalıdır. Yani sözlü olarak varlığını koruyamayan bir dilin kâğıt üzerindeki sembolik işaretlerde yaşamasının pek bir anlamı yoktur. Çünkü dil, temelde söz ile kaim olur.

\section{A. Siirt Arapçasında Hikâye ve Masallar}

Eskiden, Siirt'te elektrik ve televizyon gibi teknolojilerin henüz yaygın olmadığı dönemlerde insanlar geceleri mum veya gaz lambası 1şı̆̆ında, odun sobasının etrafında bir araya gelerek birbirlerine Arapça hikâyeler anlatırlard1. Bu meclislerde büyükler 'Antere b. Şeddâd'ın (ö. m. 614 [?])11 Divanını, Siretu Seyf b. Zîyezen ${ }^{12}$ diye bilinen destansı hikâyeleri, halk arasında yaygın olan bazı masalları aktarır veya bazı kasideler okur, çocuklar da ilgi ve heyecanla bu anlatıları dinlerdi. Genellikle bu hikâyelerin bir girizgâhı ve sona erdiğini anlatan bir sonuç cümlesi vardır. Örneğin hikâyeye;

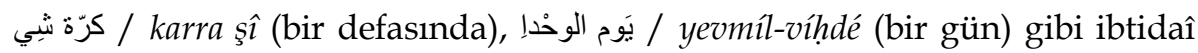

11 Annesi bir cariye olan 'Antere b. Şeddâd (ö. m. 614 [?]), Cahiliye döneminde yaşayan melez bir şairdir. Kölelikten kurtulup amcasının kızı olan sevgilisi 'Able'ye kavuşmak için bazı üstün başarılar sergilemek zorunda kalan 'Antere, düşmanın üzerine atılıp kahramanca savaşmış ve mensup olduğu 'Abs kabilesini cesurca savunmuştur. Bir muallakâsı ve kahramanlıklarının anlatıldığı bir divanı vardır. Hayatına dair geniş bilgi için bk. Cemal Muhtar, "Antere", Türkiye Diyanet Vakfi İslâm Ansiklopedisi (DİA), (İstanbul, Türkiye Diyanet Vakfı, 1991), III, 237.

12 Sîretu Seyf b. Zîyezen hikâyeleri; İslamiyet'ten önce Peygamberin geleceğine inanan ve ona iman eden Seyf adındaki bir karakterin Habeşliler'e ve zencilere karşı verdiği mücadele ile insanlar ve cinler arasında İslâm'ı yaymak için gösterdiği çabalar anlatılır. Destanımsı maceralardan oluşan bu anlatılar, diğer sîretlerin aksine insanların ve cinlerin bir arada yaşadığı, büyücü ve sihirbazların iktidar mücadelelerine giriştiği ve doğa güçlerini ele geçirmek için savaştı̆̆ı, evrenin dışında mistik, hayalî ve efsanevî bir âlem çizmektedir. Müellifi ve yazılış tarihi hakkında çeşitli rivayetler olan bu efsaneler özellikle Arap dünyasında asırlarca dilden dile anlatılagelmiştir. Geniş bilgi için bk. Hüseyin Yazıcı "Sîretü Seyf b. Zîyezen", Türkiye Diyanet Vakfi İslâm Ansiklopedisi (DIA), (İstanbul, Türkiye Diyanet Vakfı, 2009), XXXVII, 271. 
cümlelerle başlanır. Bunun yanında bazen de masalların başında şöyle bir başlama peşrevi söylenirdi:

\section{$\underline{\text { Siirt Arapçası }}$}

\begin{tabular}{|c|c|}
\hline كا في ما كا في & $K \hat{e} f i$ mê $k \hat{e} f \hat{~}$ \\
\hline & Akbar mín Allâ mê fì \\
\hline لا لو ذنب أو خطية & Lê lî zenb $\hat{u}$ hatiyyê \\
\hline حَيْ قُلْ استغفر الله & \\
\hline
\end{tabular}

\section{Türkçesi}

Bir varmış bir yokmuş

Allah'tan büyük yoktur

Günah veya hatası olan

Estağfirullah desin

Siirt Arapçasında masallar, Türkçe masalların sonunda söylenen "gökten üç elma düştü... veya onlar ermiş muradına..." ifadelerine benzeyen tûfé tûfé intemmét il-hentelûfé şeklinde bir ifade ile sonlandırılır. ${ }^{13}$

Aşağıda Siirt Arapça diyalektiyle anlatılmış bazı hikâye ve masallar, Türkçe tercümeleriyle birlikte verilecektir.

Ísrâf bele te'eb: Kê fî véhét kên zengîn $\hat{u}$ ibnûu kên misrôf. Kíl yevm şî le kê

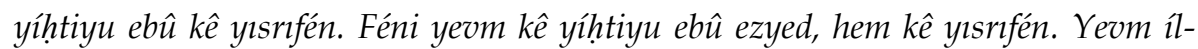
víhdé ebû yíllu "Mê baka bî̀î şî dehtîk." Immu tíbdî êvi'l-karra tíhtiyu ışveyyé. Âk ımminé yíntem. Yincıbor íl-veled î rọh yi'mél. Evvel mê yícî mín ış-şı̆gél $\hat{\imath}$ cîb mecîdiyé yırviya şê ebû. $\hat{I}$ kûl: "Talloh cíbtu mecidiye il-yevm!". Ebû yímsék îmecîdiyé dî ziccce mín íl-pancara. Heme íl-veled yımsék îdû. Î kîul: "Ewe mín is-

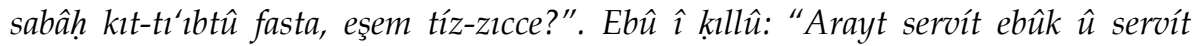
ımmôk? Evlé killitén ket-pevtuhén, ket-roh tıhricên fì afâr le mô yılzém. Ísrâf bele te'eb." 14

Emeksiz israf: Oğlu müsrif olan zengin bir adam vardı. Her gün babasının verdiği parayı harcardı. Ertesi gün babası daha fazlasını verince onları da harcardı. Bir gün babası ona "Sana verecek param kalmadı." der. Bu defa annesi ona bir müddet para vermeye başlar. Sonunda bu da tükenir. Çocuk mecbur kalır çalışmaya başlar. İşten döner dönmez getirdiği bir mecidiyeyi babasına gösterir ve der ki: "Bak bugün bir mecidiye kazandım!" Bunun üzerine babası elindeki bir mecidiyeyi alıp camdan atmaya çalışır. Çocuk hemen babasının elini tutar ve: "Sabahtan beri bunu kazanmak için uğraştım, onu nasıl atarsın!” der. Bunun üzerine babası ona: “Anne-babanın

13 Cengiz, "Siirt Arapçasını Yaşatmak", 260.

14 Anlatan: M. Ali Arl, Bk. https://www.youtube.com/watch?v=ibJ2GeMs7hw (Erişim Tarihi: 31.03.2019). 
servetine nasıl davrandığını gördün mü? O serveti çarçur ediyor ve gereksiz yerlere harciyordun. Bu, emeksiz israftır." der.

Nétinê: Yeom il-vihdé ll-mara û ır-racôl kíl-hírdû min ba'wén. Kíl-hírdû mô yígrev me'e ba'wén. Û lîhén şiğel ímné fíl-karm. Kır-râhûu ll-karm. Û me'én ı̣hmâr imné. îl-lhmâr kinhel makvadû û di yıhrôp. Ûvé kıssallû hey û iyé kıssârôt karîbıt íl-

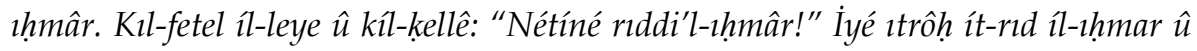

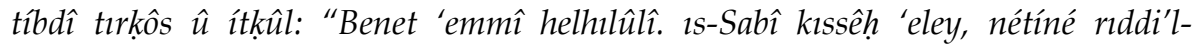
ıhmâr!.."15

Kokuşmuş: Bir gün kar1-koca birbirlerine küsmüşler. Küsmüş, hiçbir şekilde birbirleriyle konuşmuyorlarmış. Bağda da işleri varmış. Yanlarında bir merkeple bağa gitmişler. Eşeğin yuları çözülmüş ve kaçmak üzereymiş. Adam durumu fark etmiş ve eşi merkebe yakınmış. Ona dönmüş ve "Kokuşmuş, merkebi tut!" diye bağırmış. Bunun üzerine karısı merkebi yakalar ve şöyle diyerek oynamaya başlar: "Ey amcakızlarım beni zılgıtlarla tebrik edin! Zira herif bana; 'Kokuşmuş merkebi yakala!' diye seslendi."

Siirt yöresinde yaşayan Arapların asırlardır birbirlerine anlattıkları ve nesilden nesile aktardıkları daha nice hikâye ve masalları vardır. Bu hikâyelerin pek çoğu derlenip kayıt altına alınmadıkları için unutulup yok olmuştur. Lehçeyi ayakta tutan en önemli unsurlardan birisi olan bu değerlerin bir an evvel sahadan derlenip kayıt altına alınması ve muhafazasının sağlanmas1 gerekmektedir. Aksi takdirde sadece hikâyeler değil, bu dilin kelime hazinesi, karakteristik özellikleri ve canlılı̆̆ı giderek zayıflayacaktır. Son yıllarda bu tehlikenin farkına vararak Siirt Arapçasının korunması gerektiğine inanan ve bu dilin araştırmaya değer bir hazine olduğunu düşünen araştırmac1lar, sahadan birtakım hikâye ve masalları derleyip neşretmeye başlamışıı. ${ }^{16}$ $\mathrm{Bu}$ tür çalışmaların son derece önemli ve gerekli olduğunu düşünmekle birlikte henüz istenen düzey ve sistematiğe sahip olunmadığını ifade etmek gerekir. Dolayısıyla ele alınan bu çalışmanın en önemli amaçlarından birisi de Siirt Arapçasının söz konusu değerlerini kayıt altına alarak bu dilin korunması ve yaşatılmasına katkı sağlamaktır.

15 Anlatan: M. Ali Arı, https:// https://www.youtube.com/watch?v=YOOYPMyyvt8 (Erişim Tarihi: 01.04.2019).

16 Örnek için bk. M. Şefik Görgin, Arapça Qëltu Lehçesi Siirt Arapçası ('Arabî l-Welêyé), 1. bs., (Kocaeli: Özlem Ofset Matbaa, 2017), 211-246; Abdulhadi Timurtaş, "el-Mevrûs eş-Şa'bî li 'Arab Es'ird", Dirâsât fi'lLehecâti'l-'Arabiyye el-Mehkiyye fì Türkiye, 1. bs., ed. Yaşar Acat, (İstanbul: Akdem Yayınlar1, 2018), 139-142. 


\section{B. Siirtli Arapların Bazı Adetleri}

Siirt Arapça diyalektinin sözlü kültür unsurlarında dinî motifler oldukça yoğun bir şekilde işlenmiştir. Örneğin yağmur için okunan dualarda geçen ifadeler zamanla iktibas edilerek atasözlerinde kullanılmaya başlan-

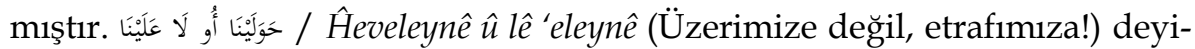
mi buna bir örnek olarak gösterilebilir. Zira bu deyimde, olası olumsuzlukların üzerimize değil etrafımıza gelmesi temenni edilmektedir. ${ }^{17} \mathrm{Bu}$ ifadenin, uzun süren yağmurun dinmesi için Hz. Peygamber (s.a.v.)'in okuduğu " اللَّمَ

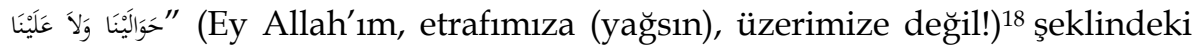
duasından mülhem bir atasözü olduğu kanaatindeyiz.

Dinen yapılan yağmur duasının dişında gençler özellikle yaz veya sonbahar aylarında her tarafta kuraklığın kendisini iyice hissettirmesiyle, kendi lisanlarıyla yağmurun yağmasını talep ederlerdi. Özellikle havada bir takım bulut kümelerini gören gençler heyecanlanır, bu bulutların bir rahmet indirmeden geçip gitmesini istemedikleri için yüksek sesle şu ifadeleri tekrarlardı: 19

\section{Siirt Arapçası}

Ğeyfê ğeyfê ğeyfine

Rabbî matar ihtînê

Vêdî Ríhé kín-nişéf

Rầînâ $\hat{u}$ 'iç̧ên

\section{Türkçesi}

Ey yağmur bulutları bizi sırılsıklam 1slatin

Rabbim yağmur ver bize

Zira Rihê vadisi kurumuş

Çobanımız da susamıştır.

Sözlü kültür unsurları, Siirt Arapça lehçesinin korunmasında önemli bir rol üstlenmiştir. Zira bazı Arapça kelimelerin yerine, zamanla diğer dillerden ödünç alınan sözcükler kullanılırken, söz konusu kelimelerin sözlü kültür ürünlerinde orijinal şekilleriyle yaşamaya devam ettiği görülmüştür. Örneğin yukarıdaki dörtlükte geçen $r \hat{a} \hat{\imath}$ (çoban) kelimesinin yerine hali hazırda Rıstâk bölgesinde genellikle Kürtçeden ödünç alınan şivân sözcüğü kullanılmakta iken, bu kelimenin sözlü kültür ürünlerinde orijinal şekliyle korunması dikkat çekicidir. Bu durum, sözlü edebiyatın dili ayakta tutan en önemli dayanaklardan birisi olduğunu göstermektedir.

\footnotetext{
17 Ayhan Mergen, Siirtlinin Gönlünden Diline Yanslyan Atasözleri ve Deyimler Arapça Söylenişleriyle, (Siirt: Özel Basım, 2017), 44.

18 İlgili hadis için bk. Buhârî, Cumâ/35.

19 Tekin Cengiz (Doğum 1986 İkizbağlar (Tôm köyü)/Tillo) ile yapılan 02.04.2019 tarihli mülakat.
} 
Cumhuriyetin ilk yıllarında Siirt'te Musa Kazyaği gibi meşhur tellallar vardı. Herhangi bir şey kaybolduğunda bunun ilanını şu ifadelerle yaparlard1:

\section{Siirt Arapçası}

'Elê hııb Alla û $\imath n-N e b \hat{\imath}$

Min kíl-ara ıhmâr geor

Yihtiyu şê sahabû

Lihû nôtê helêl.

\section{Türkçesi}

Allah ve Peygamber aşkına

Kim gri bir merkep görmüşse

Sahibine teslim etsin

Bir banknot almaya hak kazansin

Bu tellallar başlangıçta Siirt'in sokak ve caddelerinde Arapça ilan yaparken tek partili dönemde Arapça konuşmak yasaklanınca bu ilanlar Türkçe yapılmaya başlanmıştır.

\section{Siirt Arapçasında Bilmece ve Tekerlemeler (Ḥazzôriya)}

Bilmece ve hazzôriya denen tekerlemeler, Siirt Arapça diyalektinin en önemli sözlü edebiyat ürünlerindendir. Aşağıda söz konusu diyalektte kullanılan bilmecelere örnek verilmiştir.

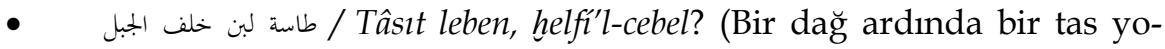
ğurt?)

Cevap: Ay.

- حيّة حبل بين الجبل / heyyé hebel, beyníl-cebel? (Dağlar arasında yılan gibi kıvrılan şey?) Cevap: Nehir veya yol. ${ }^{20}$

Siirt yöresinde yaşayan Arapların sözlü kültür unsurlarından bir tanesi de tekerlemelerdir. Aşağıda Siirt Arapçasında kullanılan tekerlemelere örnek verilmiştir.

\section{Siirt Arapçası}

Fûré pûré

Beyt hemmet sûlé

Êti'l-mehsûlé

Êwi'l-'eccêné

Êwi'l-hebbêzé

Êwi pambé pmbé

$\hat{E} w i$ firr 'int 'ammo heccî

\section{Türkçesi}

Fure pure (bir anlamı yok)

Hammet Sêlé' nin evi

$\mathrm{Bu}$ (serçe parmağı) yıkayan

$\mathrm{Bu}$ (yüzük parmağı) yoğuran

$\mathrm{Bu}$ (orta parmak) pişiren

$\mathrm{Bu}$ (işaret parmağı) pembe pembe olan $\mathrm{Bu}$ da pır pır etmiş Hacı Amcaya gitmiş

20 Cengiz, "Siirt Arapçasını Yaşatmak", 259. 
Siirtliler ışgor denen nevruz günü rayoş $\hat{u}$ mıkétîp ${ }^{21}$ ve côkât (bumbar) gibi yöresel yemekler pişirip damlarda lambalar yakmak suretiyle bugünü kutlarlardı. Bu kutlamalarda ellerindeki lambaları dairesel olarak çevirip şu tekerlemeyi söylerlerdi:22

\section{Siirt Arapçası}

'Elê kahôr íl-keşşe

Íl-leylé mô yit'eş̧⿻

'Ele kahôr besîsé

Hiryû bêlû fi'l-kîsé

\section{Türkçesi}

Papazın inadına

O bu gece yemek yemeyecek

Besisenin ${ }^{23}$ inadına

Kesenin içine ettiler

Siirt'te bahar geldiğinde çocuklar evleri dolaşıp şu tekerlemeyi söyleyerek, bu evlerden kuru üzüm ve ceviz gibi yemişler talep ederlerdi:24

\section{Siirt Arapçası}

Cînê cinê cînê cinê cinê

Cînê límhellítkén límhellitkén

Alla î helli límmû hellî límmî

Ímmî sebeh î̉nîn sebeh î́nîn

\section{Türkçesi}

Geldik, geldik, geldik, geldik, geldik.

Mahallenize geldik mahallenize

Allah onu annesine bağışlasın annesine

Annesine yedi erkek yedi erkek evlat

Her biri mercan boylu mercan boylu

İnşallah Sultan gelir Sultan gelir

Çadırlarını kurar, çadırlarını

Bizim tarafımıza bizim tarafımıza

Bostanlarımızı sular, bostanlarımızı

Ey amca beni götür!

Babamın evine

Ey amca beni götür!

Babamin evine

'Imeydiye' de olan

Tabî sokağında

Afiyet mafiyet

Ízveyye'de oturuyorlar

Kuru üzüm ve ceviz içi getir

\footnotetext{
21 Rayoş û mıkétîp; içerisine kavrulmuş un ve ceviz içi konup börek gibi sarılan yufkaların yağda kızartıldıktan sonra pekmeze batırılmasından sonra servis edilen Siirt'in eski bir tatlısıdır. Yapılışı hakkında geniş bilgi için bk. Cumhur Kılıççığlu, Her Yönüyle Siirt, (Ankara: Kadığlu Matbaası, 1992), 105.

22 Cumhur Kılıççıŏlu (Doğum 1938 Siirt) ile yapılan 20.06.2018 tarihli mülakat.

23 Un ve yağla yapılmış yöresel ve pratik bir yiyecek, atıştırmalık. (Tekin Cengiz ile yapılan 02.04.2019 tarihli mülakat.

24 Anlatan: M. Ali Arı, https://www.youtube.com/watch?v=hQEa0d9dwJk (Erişim Tarihi: 01.04.2019).
} 
Dinnakkor işveyyé

Yê cevêp yê mevêp
Biraz atıştıralım

Hadi cevap mevap (ver)

Yine nevruz veya aşure günlerinde çocuklar komşuların evlerini dolaşıp şu tekerlemeyi söylerlerdi: ${ }^{25}$

\section{Siirt Arapçası}

Cînê mê cînê

Hill îl-kîs u-htînê

Bêb iş-şéh iroînâ

Hevlim hevlim helf il-heyt

Alla î hellî nés îl-beyt

Linê 'ecin kl-ḩtamar

Likén ibén kemel-kamar

Yê cevêb yê mevêp

\section{Türkçesi}

Gelir gelmez

Keseyi aç ve bize ver

Şeyhin evini göster bize

Duvarın arkasında meşaleler

Allah ev halkını bağışlasın

Mayalanan bir hamurumuz var

Ay gibi bir çocuğunuz var

Hadi cevap mevap (ver)

Ancak günümüzde bu adet ve geleneklerin birçoğu terkedilmiştir. Dilin ve kültürün en önemli taşıyıcılarından olan bu dil malzemesinin giderek kaybolması Siirt Arapçasının da günden güne zayıflamasına neden olmaktadir.

\section{Bazı Öğüt Verici Manzumeler}

Siirt'te 1950'li yıllara kadar halk arasında söylenen bazı manzumeler vardı. Bunların yaşlı amcalar tarafından gençlere öğüt maksadıyla söylendiği aktarılmaktadır. Şu an bu şiirleri bilen çok az insan kalmıştır. Dolayısıyla bu tür edebi mahsullerin kayıt altına alınması bu çalışmanın hedefleri arasındadır. Aşağıda bu manzumelere örnek verilmektedir:26

\section{$\underline{\text { Siirt Arapçası }}$}

Bêlôk $\hat{u}$ bêlôk eĥ̀

Min veld ız-zıné27 bêlôk

Le't-'âşôr veld ız-zıné

Dî harrôp eş̆ĝelôk

\section{$\underline{\text { Türkçesi }}$}

Ey kardeşim dikkat et!

Veled-i zina kişilere dikkat et!

Veled-i zina kişilere refakat etme

Yoksa işlerini mahveder

\footnotetext{
25 Anlatan: M. Ali Arı, https://www.youtube.com/watch?v=hQEa0d9dwJk (Erişim Tarihi: 01.04.2019).

26 Anlatan: M Ali Arı, https://www.youtube.com/watch?v=wZoPraKKaZA (Erişim Tarihi: 01.04.2019).

27 Siirt Arapçasında veld ız-zıné (veled-i zina) ifadesi genellikle karaktersiz ve üç kağıtçı kişiler için kullanılan bir tabirdir.
} 
İnkê fihıklok veld ız-zıné

Tabbıklû ecfênôk

Velev heleflôk bil-yemîn

$B a^{\prime} e^{\prime} l$-yemîn hênôk
Veled-i zina kişi sana gülümserse

Ona suratını as

Sana yemin etse bile

Yeminden sonra ihanet eder

Aynı şekilde aşağıda Siirt Arapçasında söylenen öğüt verici manzumelere bir başka örnek verilmiştir. ${ }^{28}$

\section{$\underline{\text { Siirt Arapçası }}$}

Yê tayr û yê tayr

Bessôk ut'ellî kad mê bakâlôk ra's

Memdôh û beyn is-sicar

Meokûs beyn in-nés

Tiffêhitnê kın-cenêt

Beynel-kedeh û $\imath l-k e$ 's

\section{Türkçesi}

Ey keklik, hey keklik!

Yeter yükselecek başın kalmadı

Ağaçlar arasında övülen

İnsanlar arasında yerilen

Elmamızı toplamışlar

Kâse ve kadehler içinde

Aramızda geçen konuşmayı

İnsanlara anlatma

Gerîle ki'n-gere beynetnê

Lêt-kîulû şen-nês

\section{E. Siirt Arapçasında Atasözleri}

Atasözü, ataların gözlem ve tecrübeleri neticesinde vardıkları kanaatleri son derece veciz bir üslupla ve çoğu zaman öğüt verici olan, sözlü gelenek içerisinde şekillenen ve asırlar boyunca kalıplaşmış olarak aktarılan anonim karakterli sözlerdir. ${ }^{29}$ Siirt yöresinde yaşayan Arapların zengin bir sözlü kültür dağarcıkları vardır. Hiç şüphesiz bunların başında da atasözleri gelir. Bu atasözlerinin içerisinde toplumun dünya görüşünü yansıtan çok önemli ipuçları vardır. En önemlisi de atasözleri kendilerine has yapıları sayesinde asırlar boyunca bozulmadan bir kalıp halinde nesilden nesile aktarılabilmiştir. Böylece lehçenin kelime hazinesi, karakteristik özelliği ve fonetik yapısı bu sözlü kültür ürünleri sayesinde bozulmadan aktarılabilmiştir. Aşağıda Siirt Arapçasının bu zengin atasözü hazinesinden birkaç örnek verilmiştir.

\footnotetext{
28 Anlatan: M. Ali Arı, https://www.youtube.com/watch?v=wZoPraKKaZA (Erişim Tarihi: 01.04.2019).

29 Bk. Ahmet Köklügiller, Türkçe Edebiyat Sözlü̆̆̈̈, (İstanbul: Hür Yayınevi, 1974), 15.
} 
هرب من تحت المطر ارتى تحت المزريب Harap min teht il-matar, ırtamâ teht íl-mezrîp (Yağmurdan kaçtı, oluğun altına düştü.): Kötü bir durumda olan insanların, bu durumdan kurtulmak için çaba harcamalarına rağmen, bazen daha kötü durumlara düşebildiklerini anlatmak için kullanılır. Bu atasözünün Siirt Arapçasında Harap mín teht tt-tawiyé, ırtama teĥt ll-vekfé (Sağanaktan kaçıp oluğun altına düştü.) şeklinde farklı bir kullanımı da bulunmaktadır. ${ }^{30}$ Türkçede kullanılan "Yağmurdan kaçarken doluya yakalandı." atasözüyle çok yakın bir benzerlik arz etmektedir.

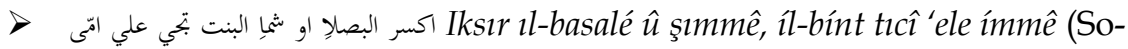
ğanı kır, kokla; kız da annesine çeker.): Soğanın kendine has bir kokusu vardır. Bu atasözünde soğanın kokusunun değişmediği gibi kızların da annelerine çektiği ifade edilmektedir. Arapçada buna

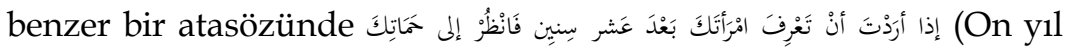
sonra eşinin nasıl olacağını bilmek istiyorsan kaynanana bak.) Bu atasözüyle kızın huy bakımından anneye çektiği, kız alırken annesine de bakılıp araştırılması gerektiği anlatılmaktadır. Bu atasözü, Türkçede kullanılan "Anasına bak kızını al, kenarına (kıyısına, tarağına) bak bezini al." 31 Atasözünü çağrıştırmaktadır.

> Alla iy hâffiznâ min se'ıt in-naksa (Allah bizi eksik saatten korusun): İnsanın hayatında olumsuz bazı anların olabileceğini, daha önce hiç hesaplanmayan bir felaketle karşı karşıya kalınabileceğini bahse konu edinen bu atasözü, bu tür olayları "eksik saat" olarak tanımlayarak yüce Allah'tan bu gibi anlardan insanları korumasını temenni etme adına zikredilmektedir. ${ }^{32}$ Siirt lehçesinde "eksik saat" tabiriyle farklı mana içeren başka bir deyim daha kulla-

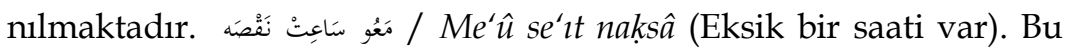
atasözü, akli dengesi yerinde olmayan ve alakasız şeyler konuşan kişiler için söylenmektedir. Türkçedeki "bir tahtası eksik." deyimi ile aynı manada kullanılmaktadır.

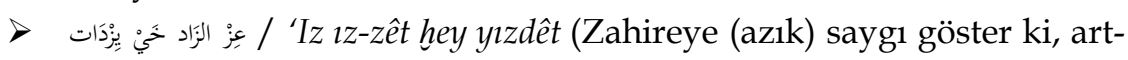
sın.): Azık anlamında kullanılan زاد (zêd) kelimesi, daha çok yöre halkının çoğunlukla tükettiği bulgur, pirinç ve yarma gibi kuru g1-

\footnotetext{
Mergen, Atasözleri ve Deyimler, 270.

Ömer Asım Aksoy, Atasözleri ve Deyimler Sözlüğ̈̈, (İstanbul: İnkılap Kitabevi, 2018), I/147.

Mergen, Atasözleri ve Deyimler, 18.
} 
dalar için kullanılmaktadır. Bu atasözünde insanların elindeki nimetlere saygı göstermeleri, israf ve savurganlık yapmamaları gerektiği anlatılmak istenmektedir. Nimete gereken saygı ve ehemmiyetin gösterilmesi halinde bereketlenip bollaşacağına dikkat çekilmektedir. 33

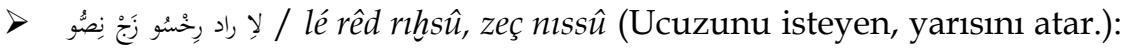
Satın alınan bir şeyin kaliteli olmasına dikkat edilmesi gerektiğini ifade eden bir atasözüdür. Bir şeyin ucuzunu isteyen kişi bunun kalitesinin de düşük olacağını göz önünde bulundurmalı hatta yarısını da dökebileceğini bilmelidir. Türkçedeki "ucuzsa vardır bir illeti, pahalıysa vardır bir hikmeti," atasözüne benzer bir mana içermektedir.

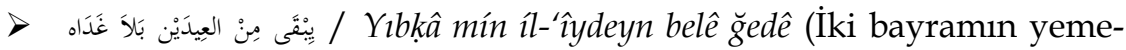
ğinden mahrum kalmak.): Aynı anda birden fazla iş yapmaya çalışıp hiçbirisinde başarılı olamayan kişiler için söylenen bir atasözüdür. Türkçede kullanılan "iki karpuz bir koltukta gitmez," atasözüne yakın bir manayı ifade etmektedir.

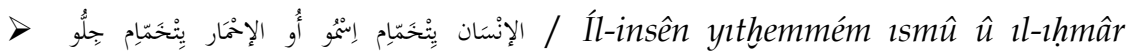
yıthemmém cıllû (İnsan adını, eşek ise semerini düşünür.): Bu atasözünde insanın namını koruması gerektiği ifade edilmektedir. Toplumda olumlu izlenimleri ve hoş bir sedayı ancak kişilik sahibi onurlu insanlar bırakabilir. Türkçedeki "eşek ölür kalır semeri, insan ölür kalır eseri," anlamındaki atasözüne çok yakın bir mana içermektedir.

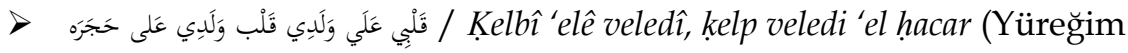
çocuğuma titrerken, çocuğumun yüreği taşa titremekte.): Bu atasözünde ebeveynin çocuklarının üzerine titredikleri, onlar için endişelendikleri; çocukların ise aynı duyguda olmadıklarından yakınımaktadır.

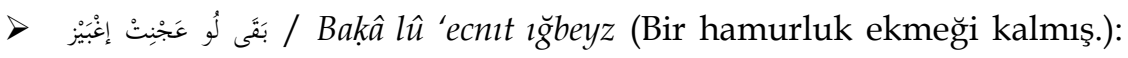
Yaşı ilerlemiş kişiler için kullanılan bir ifadedir. Bu, yaşlılara karşı yanlış tutum ve davranış içinde olan kişilere ilerlemiş yaşları hatırlatılarak onlara karşı daha sabırlı ve anlayışlı olunması öğütlenmektedir. Hayatta "bir fırın ekmeği kalmış" ifadesiyle sayılı günlerinin kaldığı anlatılmak istenmektedir.

33 Mergen, Atasözleri ve Deyimler, 289. 


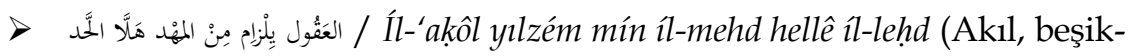
ten mezara kadar gereklidir.): Bu atasözü ile aklın insanoğlu için çok değerli bir sermaye olduğu anlatılmaktadır. ${ }^{34}$

\section{F. Siirt Arapçasında Deyimler}

Deyimler de atasözleri gibi toplumun geniş bir kitlesi tarafından benimsenmiş ve halka mal olmuş anonim ifadelerdir. Atasözleriyle pek çok benzer yönleri olduğu için çoğu zaman birbirleriyle karıştırılır. Genel bir tanım yapmak gerekirse deyim; gerçek anlamı dışında kullanılarak ifadeyi zenginleştiren iki veya daha fazla kelimeden oluşan kalıplaşmış söz dizisidir. ${ }^{35}$ Deyimleri atasözlerinden ayıran özellik, sözcük sayılarından ziyade işlev ve karakteristik yapılarıdır. Bu anlamda deyimler, bir durumu daha veciz bir şekilde anlatmaya yarayan, öneri veya öğüt içermeyip sadece durum tespiti yapan ve genellikle birden fazla sözcükten oluşan ifadelerdir. ${ }^{36}$

Siirt Arapça diyalektinin sözlü kültür ürünlerinden birisi de deyimlerdir. Bu deyimler, asırlardır birer kalıp olarak günümüze kadar nakledile gelmiştir. Bu ürünler, lehçenin geçmişi ile sıkı bir bağ kurmuş ve diş etkenlere karşı korunmasını sağlamıştır. Aşağıda bu deyimlerden birkaç örnek verilmiştir.

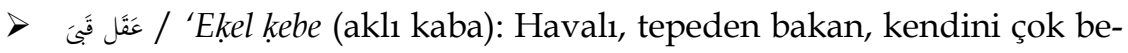
ğenen, başkalarına üstten bakan kişiler için kullanılan bir deyimdir. ${ }^{37}$ Türkçedeki "burnundan kıl aldırmamak" deyimine benzer bir anlam taşımaktadır. Bu deyim, bu vasfa sahip insanlarla diyaloğa girmenin zor bir durum olduğunu ifade eder. Siirt merkez ve Fírsêf' teki Araplar bu deyimi 'eqol qebe şeklinde telaffuz ederler.

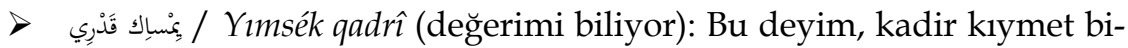
len başkalarına hak ettikleri değeri veren ve nankör olmayan kişiler için kullanılır.

> أُواً عَلى نَار / Uvé 'el nâr (ateş üstünde): Bu deyim, telaşl1, aceleci ve sabırsız kişiler için kullanılır. Türkçede kullanılan "diken üstünde" deyimine yakın bir anlam içermektedir.

\footnotetext{
4 Mergen, Atasözleri ve Deyimler, 14.

35 Osman Göker, Uygulamalı Türkçe Bilgileri I, (Ankara: MEB Yayınları, 2001), 207.

36 Erdinç Doğru, Dilin Derin Devleti Deyimler, 1. bs., (Ankara: Fecr Yayınları, 2011), 29.

37 Mergen, Atasözleri ve Deyimler, 14.
} 
$>$ حَبلُو أُو طَوِيل / Hebelû û tavîl (ipi uzundur): Bu deyim, işini umursamayip ihmal eden, kendisinden istenilen işi vaktinde yapmayan kişiler için kullanılır. ${ }^{38}$ Yine Siirt Arapçasında kullanılan صَبْرُ أُو طَوِيل tavîl (sabrı uzundur) ifadesi de buna benzer başka bir deyimdir.

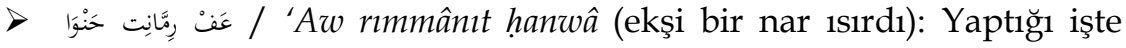
umduğunu bulamayan, beklentisini karşılayamayan kişiler için kullanılır. Girdiği işten zarar gören veya bazı meselelerde işin içinden çıkamayan kişiler için kullanılan bir deyimdir. ${ }^{39}$

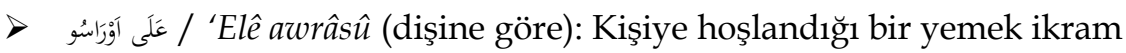
edildiğinde veya tam kafasına göre bir kişi, iş ve durumla karşılaştığında söylenen bir deyimdir.

$>$ سين مَلُّس / Seyn mellûs (kaygan dilli): Konuşması kimseyi rahatsız etmeyen, tatlı dilli olan kişiler için kullanılır. Bazen de yağcılık yapıp menfaat peşinde olan ve yalakalık yapan kişileri tavsif ederken kullanilır.

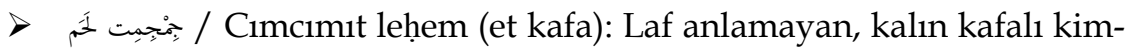
seler için kullanılan bir deyimdir. ${ }^{40}$

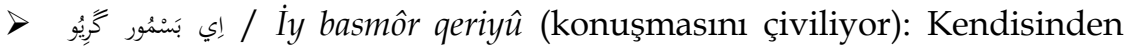
emin, diksiyonu düzgün ve hitabeti güçlü olan kişiler için kullanılır. Bazen de iğneli konuşup muhatabın canını sıkacak sözler söyleyen kişiler için de söylenir. ${ }^{41}$

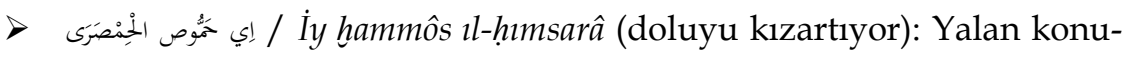
şan ve konuşmasında olmadık şeyler anlatan insanlar için kullanılan bir deyimdir. Doluyu kızartmanın mümkün olamayacağı gibi bu tür insanların sözlerinin de gerçekçi olmadığına vurgu yapılmaktadır. ${ }^{42}$

\section{Sonuç}

Anadolu'nun kimliğini oluşturan en önemli unsurlardan birisi, sahip olduğu zengin dil çeşitliliğidir. Siirt yöresinde konuşulan Arapça diyalekti bu değerlerden birisidir. Arapçaya ait bir lehçe olan bu dil, yazılı bir sisteme dayanmadığı gibi asırlardır nesilden nesile şifahen aktarılmaktadır. Salt

\footnotetext{
38 Mergen, Atasözleri ve Deyimler, 152.

39 Tekin Cengiz (Doğum 1986 İkizbağlar (Tôm köyü)/Tillo) ile yapılan 02.04.2019 tarihli mülakat.

40 Mergen, Atasözleri ve Deyimler, 105.

41 Mergen, Atasözleri ve Deyimler, 179.

42 Mergen, Atasözleri ve Deyimler, 93.
} 
sözlü kültüre dayanan dillerin ses ve hareket alanı bakımından avantajlı olmalarının yanında dış etkenlere karşı savunmasız olmak gibi dezavantajları vardır. İletişime geçilen diğer kültür ve diller, zamanın şartlarına göre değişen dünya algısı ve yaygınlaşan tüketim kültürü gibi pek çok diş faktör, yazılı bir sistemi olmayan dilleri daha fazla etkilemiştir. Dolayısıyla Siirt Arapça diyalekti dış etkenlere karşı uzun süre savunmasız kalmıştır. Bunun neticesinde bu dilin hem yapı hem fonetik açıdan birçok değişikliğe maruz kaldığ1 görülmüştür.

Hiç şüphesiz bir yazılı sistemi olmayan Siirt Arapçasının en önemli dayanağ1 sahip olduğu zengin sözlü kültür hazinesidir. Zira bu özelliği sayesinde birden çok aşındırıcı faktöre karşı doğal bir savunma geliştirmiştir. Lehçenin sahip olduğu atasözleri ve deyimler bir kalıp halinde değişmeden nakledildiği için bu ürünlerin içerdiği dil malzemesinin korunmasını sağlamıştır. Ayrıca hikâye ve masalların anlatım dili, lehçenin cümle yapısını ve kelime hazinesini muhafaza etmiştir. Yine Siirtli Arapların zengin örf, adet ve kültürleri, dillerinin muhafazasına ve yaşatılmasına büyük oranda katkı sağlamıştır.

Son yıllarda Siirt Arapça diyalekti için bir yazı dili oluşturma çabalarının olduğu bilinmektedir. Bu lehçeye bir yazı dili kazandırmak ve sahip olduğu birçok dil unsurunu kayıt altına almak da bu dili yaşatmaya yetmeyebilir. Bunun yanında bu dilin aktif bir şekilde kullanılmasının sağlanması gerekmektedir. Zira kullanılmayan bir dil her ne kadar kâğıt üzerinde yazılı olsa da ölüdür.

\section{Kaynakça}

Aksoy, Ömer Asım. Atasözleri ve Deyimler Sözlüğü. İstanbul: İnkılap Kitabevi, 2018.

Arı, M. Ali. https://www.youtube.com/watch?v=ibJ2GeMs7hw (Erişim Tarihi: 31.03.2019).

. https:// https://www.youtube.com/watch?v=YOOYPMyyvt8 (Erişim Tarihi: 01.04.2019).

https://www.youtube.com/watch?v=hQEa0d9dwJk (Erişim Tarihi: 01.04.2019)

https://www.youtube.com/watch?v=tYoa6Hn1XfM (Erişim Tarihi: 01.04.2019). 
https://www.youtube.com/watch?v=wZoPraKKaZA (Erişim Tarihi: 01.04.2019).

Bituna, Gabriel. Morfo-Sintaxa Dıalectului Arab Nord-Mesopotamian Din Siirt, Turcia. Bükreş: Bükreş Üniversitesi Yayınevi, 2016.

el-Buhârî, Ebû Abdillâh Muhammed b. İsmâîl b. İbrâhîm el-Cu'fî. Sahîhu'l-Buhârî (IIII), Kahire: Mektebetu's-Safâ, 2003.

Cengiz, Emin. "Siirt Arapçasını Yaşatmak”, Türkiye'de Konuşulan Arap Diyalektleri, ed. Yaşar Acat, 1. bs., İstanbul: Akdem Yayınları, 2018.

"Türkçenin Siirt Arapçasına Etkisi”, Dil Bilimleri Klasik Sorunlar-Güncel Tartışmalar, ed. M. Nesim Doru, Ömer Bozkurt, Ankara: Mardin Artuklu Üniversitesi Yayınları, Mardin Sesi Gazetecilik Matbaacılık Yayıncılık, 2018.

Cengiz, Tekin. (Doğum 1986 İkizbağlar (Tôm köyü)/Tillo) ile yapılan 02.04.2019 tarihli mülakat.

Doğru, Erdinç. Dilin Derin Devleti Deyimler. 1. bs., Ankara: Fecr Yayınları, 2011.

Göker, Osman. Uygulamalı Türkçe Bilgileri I. Ankara: MEB Yayınları, 2001.

Gül, Ahmet. "Sahâbe Tefsirinde Dil Olgusu", XII. Tefsir Akademisyenleri Koordinasyon Toplantısı: Kur'an ve Sahâbe Sempozyumu (22-23 Mayıs 2015/Sivas), ed. Hasan Keskin, Abdullah Demir, (Sivas 2016), 202.

Görgin, M. Şefik. Arapça Qëltu Lehçesi Siirt Arapçası ('Arabî l-Welêyé). 1. bs., Kocaeli: Özlem Ofset Matbaa, 2017.

Gül, Necim. Siirt Arapçasını Kurtarmak. yy: Sage Matbaacılık, 2013.

Keser, İnan ve Seyidoğlu, Sadullah. Türkiye'nin Doğusunda Araplar. 1. bs., Ankara: Karahan Kitabevi, 2018.

Kılıççıŏlu, Cumhur. Her Yönüyle Siirt. Ankara: Kadıŏlu Matbaası, 1992.

Kılıççığlu, Cumhur. (Doğum 1938 Siirt) ile yapılan 20.06.2018 tarihli mülakat.

Köklügiller, Ahmet. Türkçe Edebiyat Sözlüğ̈̈. İstanbul: Hür Yayınevi, 1974.

Mergen, Ayhan. Siirtlinin Gönlünden Diline Yansıyan Atasözleri ve Deyimler Arapça Söylenişleriyle. Siirt: Özel Basım, 2017.

Muhtar, Cemal, “Antere", Türkiye Diyanet Vakfi İslâm Ansiklopedisi (DİA), İstanbul, Türkiye Diyanet Vakfı, 1991, III, 237.

Ong, Walter J. Sözlü ve Yazılı Kültür Sözün Teknolojileşmesi. 6. bs., çev. Sema Postacıŏ̆lu Banon. İstanbul: Metis Yayınları, 2018.

Salmış, Ferman. Türkiye'nin Dil Hafizası. 1. bs., ed. Suat Hayri Küçük, İstanbul: Librum Kitap, 2015.

Timurtaş, Abdulhadi. "el-Mevrûs eş-Şa'bî li 'Arab Es'ird", Dirâsât fi'l-Lehecâti'l'Arabiyye el-Mehkiyye fi Türkiye, 1. bs., ed. Yaşar Acat, İstanbul: Akdem Yayinlar1, 2018. 
Yazıc1, Hüseyin. "Sîretü Seyf b. Zîyezen", Türkiye Diyanet Vakfi İslâm Ansiklopedisi (DİA), İstanbul, Türkiye Diyanet Vakfı, 2009, XXXVII, 271.

\section{Kaynak Kişiler:}

Ayhan Mergen (Doğum 1957 Siirt)

Cumhur Kılıççığlu (Doğum 1938 Siirt)

M. Ali Arı (Doğum 1940? Siirt)

Tekin Cengiz (Doğum 1986 İkizbağlar (Tôm köyü)/Tillo) 
Doi: 10.34247/artukluakademi.558047

\section{Emin Cengiz}

The Role of the Oral Culture in the Protection of Siirt Arabic Dialects

Citation/@: Cengiz, Emin, The Role of the Oral Culture in the Protection of Siirt Arabic Dialects, Artuklu Akademi 2019/6 (1),67-88.

\section{Extended Abstract}

The most important function of language, basically a voice product, is an oral means of communication. Throughout the history of mankind, only few from thousands of languages spoken had been recorded. Even today, many spoken languages have not been able to create a written literature. For instance, the earliest Arabic records only date back to the revelation of The Quran, although it is one of the ancient languages in the world. The Qur'an and the language of the Islam had a profound effect on composing a recorded Arabic literature. Thanks to the Quran, Arabic language, which took its final form with the expansion of Islam, made great progress and was taken under protection by the Muslim community. As a result of this process, Arabic has not become only widely spoken language but it had also produced a strong literature as well.

Anatolia, one of the significant centres of civilization in the Middle East, is a territory where different cultures lived together throughout the history. The multicultural structure of Anatolia has given rise to a diverse identity. One of the most important values constituting the identity of Anatolia is the variety in spoken language in this region. One of those languages is Arabic. Even today in Turkey, there are native Arabic speaking citizens in the Turkish Republic. It is known that this population, which has more than one million, is densely populated in the provinces such as Mersin, Adana, Hatay, Gaziantep, Kilis, Şanlıurfa, Mardin, Diyarbakır, Batman, Siirt, Muş and Bitlis. They had settled in this region for centuries ago. There are also a large number of people of Arab origin who migrated from these provinces to the big cities in the west part of Turkey. Those Arabs in the south and south-eastern Turkey are the subjects of this study, who are continuing their lives for centuries in Anatolia and those, are the people who have contributed to the formation of this region's identity. As an important reminder, it should be noted that Syrian refugees living in Turkey are excluded from this study.

A great majority of these people are bilingual and they are able to speak Turkish, Kurdish and Syriac. The dialect of Arabic speaking community is away from Standard Arabic, due to the absence of a recording system of Arabic dialects spoken in Turkey and the limited connection with the Arab world. In addition to this variation, among this community either living in the same or different residential area, there are visible differences in the dialects they spoke. Until recently, those dialect differences have not drawn the attention of the Arab World. Therefore, the native Arab linguists have carried out studies related to this new research area in recent. Since 1880s, the subject has attracted also the attention of non-Arab researchers such as Albert Socin, Haim Blanc, HansJurgenSasse, OttoJastrow, and George Grigore. 
In the province of Siirt, Arabs, Turks, Armenians, Assyrians and Chaldeans have lived together for many years. As a result of this constant contact, an interaction between the Arabic dialect and other spoken languages in the region arose. The Siirt dialect borrowed some words and even some phrases from these languages. In the meanwhile, the interaction of Siirt Arabic dialect (which also does not have a written system) with other languages, can lead to many challenges; such as been unguarded to extrinsic impacts.

Also, Arabs living in Siirt changed some Arabic letters of which the sounds are difficult to pronounce; for instance the letter 'ayn, qaf, and dha. As a result, this dialect has gained a unique structure both phonetically and morphologically. Besides this impairing process, it is also possible to talk about the dynamics that sustains the Siirt Arabic. The most important one of these dynamics is the rich oral culture and the oral tradition. Arabs living in this region have been able to preserve their language for centuries based entirely upon oral tradition without the advantages of written culture. The naturally formed oral culture has created a common memory that contains all the codes constituting the identity of the local people. This social consensus has played an important role in the preservation of this dialect and being handed down future generations.

This study focuses on the Siirt arabic dialect spoken in Siirt including the Siirt center known as the Rıstâk, a location in Siirt Tillo district, Sínép (Çatılı village in official records), Fírsef (Dereyamaç village), Halenzé (Siirt-bound Bağtepe neighborhood), Tôm (İkizbağlar village), 'Elenzok (Akyamaç village) and Fískén (Doluharman village). In this study, some examples of verbal culture products are evaluated, such as story, tale, riddles, proverbs and idioms told and used by the Arab Siirt community and the importance of these products in the survival of the dialect is emphasized. Because the proverbs and idioms of Siirt Arabic dialect were handed down throughout centuries in an unchanged form, they have ensured the preservation of the language and the material contained in these products. In addition to this, the narrated language in the stories and tales, the sentence structures and the vocabulary preserved the dialect. The rich custom and culture of the Siirt Arabs have also contributed greatly to protect and maintain their dialect. Nevertheless, today's widespread technology and changing world perception has a negative effect on oral tradition. For this reason, many old traditions and literary pieces used in the past have been gradually abandoned in Siirt. In turn, this has caused the weakened the impact of the oral culture, which is the most important basis of Siirt Arabic. Henceforth, it is among the goals of this study to record and preserve the vocabulary of the Siirt Arabic dialect. 
